\title{
IMPACT OF CLIMATE AND ANALYSIS OF DESERTIFICATION PROCESSES IN SEMI ARID LAND IN ALGERIA: USING DATA OF ALSAT AND LANDSAT
}

\author{
ZEGRAR Ahmed ${ }^{\text {a }}$ MAHI habib ${ }^{\text {a }}$; HASSANI Sid Ali ${ }^{\text {a }}$; KAROUI Sofiane ${ }^{\text {a }}$; et Al. \\ ${ }^{a}$ Centre of Spaces Techniques, CTS, BP 13, Arzew 31200 Algeria, z_ahmed65@yahoo.fr
}

\section{Commission VI, WG VI/4}

KEY WORDS: Remote sensing, SIG, ecosystem, degradation, desertification.

\begin{abstract}
:
The degradation of natural resources in arid and semi-arid areas was highlighted dramatically during this century due to population growth and transformation of land use systems. The Algerian steppe has undergone a regression over the past decade due to drought cycle, the extension of areas cultivated in marginal lands, population growth and overgrazing. These phenomena have led to different degradation processes, such as the destruction of vegetation, soil erosion, and deterioration of the physical environment. In this study, the work is mainly based on the criteria for classification and identification of physical parameters for spatial analysis, and multi-sources factors to determine the vulnerability of steppe formations and their impact on desertification. To do this, we used satellite data Alsat-1 (2009) IRS (2009) and LANDSAT TM (2001). These cross-sectional data with exogenous information could monitor the impact of the semi arid ecological diversity of steppe formations. A hierarchical process including the supervised image classification was used to characterize the main steppe formations. An analysis of the vulnerability of plant was conducted to assign weights and identify areas most susceptible to desertification. Vegetation indices combined with classification are used to characterize the forest and steppe formations to determine changes in land use. The results of this present study provide maps of different components of the steppe, formation that could assist in highlighting the magnitude of the degradation pathways, which affects the steppe environment, allowing an analysis of the process of desertification in the region
\end{abstract}

\section{Presentation of the region}

The Djelfa region belonging to the semi-arid bioclimatic, has a fairly large area of land described the phenomenon of desertification. Having a texture usually dominant sandy soils used for agricultural development (as in the great plain of Djelfa syncline), which once denied the permanent cover, will be subject to severe wind erosion. Overgrazing is a second cause of degradation and loss of land. The forested areas like the case of Djebel Sahari Senalba and consisting primarily of older forests of Aleppo pine are in a state of degradation.

\section{2 - Methodology}

To accomplish this work, we have used satellites image from ALSAT-1, IRS (2009) and LANDSAT TM (2001) combined with ground surveys. The result of this combination has allowed us to infer the impact of the semi arid ecological diversity of steppe formations. This longitudinal study based on the use of remote sensing data is to analyze the evolution of steppe ecosystems.
Satellite data used allowed us to establish thematic maps with maximum Lakewood. These are the land use map, the map soil morphology and sand cover map (extracted from the map of land) that constitute the basic maps that will serve to establish map sensitivity to desertification (CNTS, 1989). The mapping of land and boundaries of the landscape using satellite imagery at medium and resolution is the first step that allows taking stock at time t. The second step is to define and assess the potential sensitivity to desertification each indicator. Their reactions to the degradation processes are different and depend on their characteristics. The potential sensitivity of the parameter depends on the vegetation physiognomy, its biology, its rate of recovery and especially the attraction it presents to man. For morphological soil, its potential sensitivity is examined by edaphic factors such as terrain, slope, texture, salinity and siltation. The last step is the combination of the potential sensitivities modulated accessibility. Indeed, an ecosystem is not the same overall sensitivity to desertification, as is found near a water point, a road or on rough terrain. 


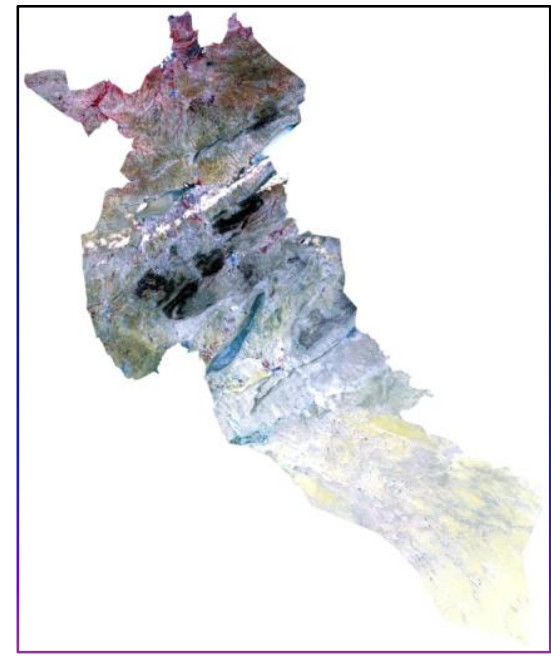

Fig. 1.2: Image IRS Djelfa 2009

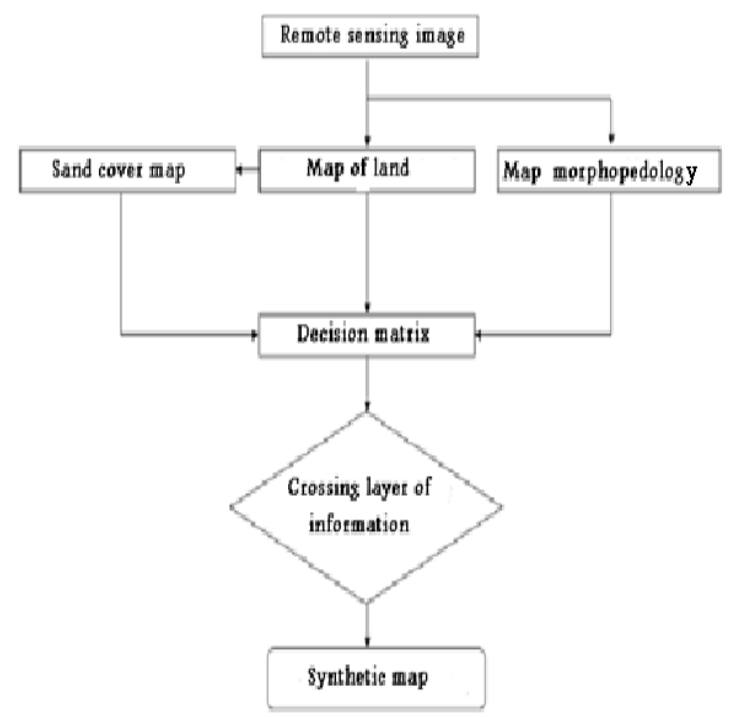

Fig. 1.1: sensitivity flowchart desertification

\subsection{Input dataset}

For this study we chose images of the TM LANDSAT 5 (2001), sensors ALSAT-1 (2009) and those of the sensor (IRS 2009), covering the study area with a landscape exposed to the phenomenon of desertification.

\subsubsection{Realization of the sensitivity map to desertification}

The realization of the sensitivity map of desertification is with a number of steps, which are the establishment of thematic maps of bases. These are formed by the morphological soil maps, land use and sand that be crossed for the mapping of partial synthesis. The information resulting from the combination of these partial summary maps will be used to establish the sensitivity map of desertification.

\subsubsection{The basic maps}

\section{- Morpho-pedological Map}

The map legend shows the major soil units. is shows dynamic morphological processes acting on these units, making account of their state of stability and evolution. To carry out this plan we have considered two important parameters are the morphology of the terrain and soil formation. The first parameter takes into account the forms of relief that arise according to slope classes, the second will also capture the state of soil degradation, its evolutionary trend in identifying soil types (raw minerals, unsophisticated, calcareous-magnesium, Isohumic allomorphic). Map Morpho pedology contributes to a direct knowledge of the areas weakened by environmental degradation.

The following chart gives an overview on the approach to achieving the morphological soil map.

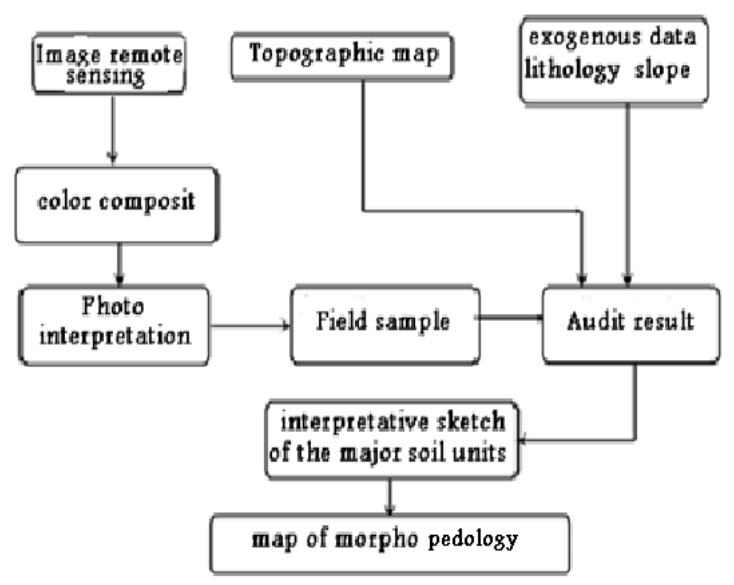

Fig. 1.3: graphic of Morpho pedology map

\section{- The map of land}

Key factor in the balance of the natural vegetation is a key element in the fight against desertification. The vegetation is particularly sensitive to environmental changes and is an indicator to reflect an ecological imbalance, natural (erosion in all its forms) which is still an imbalance related to rural development. The steppes are characterized by a type of vegetation dominated by grasses xeromorphous which do not fully cover the ground (Essentials of Plant Ecology 1978). The predominant organic form is that of perennial grasses xerophytic. It is this form of tallgrass prairie soil on unsalted (Alfa), the halophytic steppe and steppe of chotts and psamophyles the dunes. Knowledge of major vegetation types and their recovery rate is an important parameter for characterizing the degrees of sensitivity to desertification. The parameter that is taken into account in characterizing the vegetation cover is the homogeneity 
that is an indicator of the changing environment. The following chart gives an overview on the approach to the realization of the map of land.

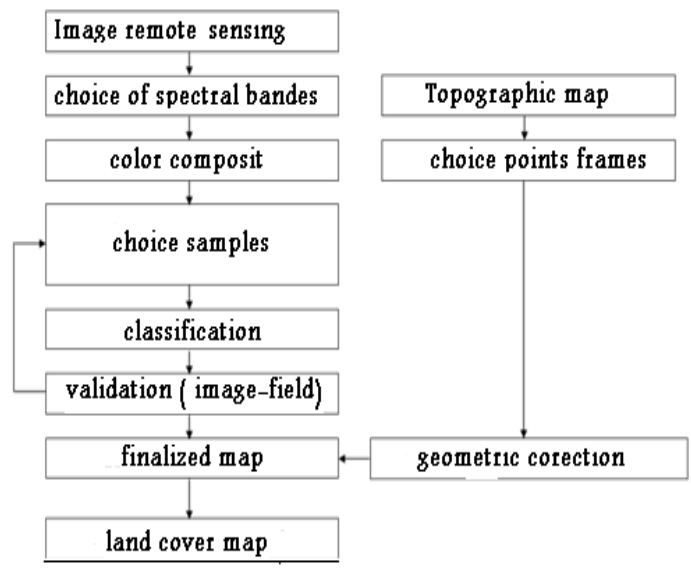

Fig. 1.4: organigram of methodology for carrying out the land cover map

\section{- Map of Sand accumulations}

The transport wind is the main mechanical agent of desertification. It is the origin of sand deposits formed into dunes. The use of satellite imaging to gauge the wind dynamics is necessary because it provides a field investigation of considerable scope. In our case the map of Sand accumulations (extracted from the map of land use) represents two distinct classes main image: the sails and sand dunes.

\section{Calculation of the Index of Sensitivity to Desertification (ISD)}

The methodology adopted for the study of sensitivity to desertification mapping and is based on a combination of three main factors involved in this phenomenon, namely the morphological soil science, land use and encroachment. Hence the desertification sensitivity is determined by an index (ISD Sensitivity Index Desertification) obtained from the product of two indices of quality of the selected factors: ILC (index land cover) and IMP (morphological index soil).

$$
\text { ISD }=(\text { ILC } * \text { IMP })
$$

\begin{tabular}{|l|c|c|c|c|}
\hline \multicolumn{1}{|r|}{ Land Cover } & VS & S & MS & LNS \\
Sand & & & & \\
\hline Very Sensitive & VS & VS & S & MS \\
\hline Sensitive & VS & S & S & MS \\
\hline Moderately Sensitive & S & S & MS & MS \\
\hline Little or no Sensitive & MS & MS & MS & LNS \\
\hline
\end{tabular}

Table 1.1: Decision Matrix
To enter information into a geographic information system, we defined a rule for the coding of the various components of the environment to establish classes of desertification sensitivity.

$$
\begin{array}{lc}
12<=\text { ISD }<=16 & \text { VS } \\
6<=\text { ISD }<=0 & \text { S } \\
2<=\text { ISD }<=4 & \text { MS } \\
\text { ISD }=1 & \text { LNS }
\end{array}
$$$$
\text { LNS }
$$
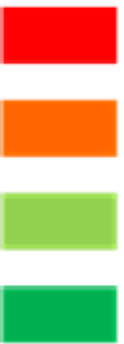

\begin{tabular}{|c|c|c|c|c|c|}
\hline \multicolumn{2}{|c|}{ ILC*IMP } & VS & S & MS & LNS \\
\cline { 3 - 6 } & 4 & 3 & 2 & 1 \\
\hline VS & 4 & $\mathbf{1 6}$ & $\mathbf{1 2}$ & $\mathbf{8}$ & $\mathbf{4}$ \\
\hline S & 3 & $\mathbf{1 2}$ & $\mathbf{9}$ & $\mathbf{6}$ & $\mathbf{3}$ \\
\hline MS & 2 & $\mathbf{8}$ & $\mathbf{6}$ & $\mathbf{4}$ & $\mathbf{2}$ \\
\hline LNS & 1 & $\mathbf{4}$ & $\mathbf{3}$ & $\mathbf{2}$ & $\mathbf{1}$ \\
\hline
\end{tabular}

Table 1.2: Determination of degrees with their respective code

\subsubsection{Determination of the sensitivity of physical parameters}

Having identified the major soil units, we conducted evaluation of the sensitivity of each class based on the slope and geomorphology (see Figure 5), and raw mineral soils not classified sensitive soils calcareous-magnesian sensitive, poorly evolved moderately sensitive and highly sensitive saline soils. Similarly for the land, the main vegetation formations located in the steppe are classified according to their type and density (see Figure 6). The forests are not classified as sensitive, the Alfa and Artemisia groups and moderately sensitive to Psamophytes, halophytes and Arthrophytum scoparium are classified very sensitive. 


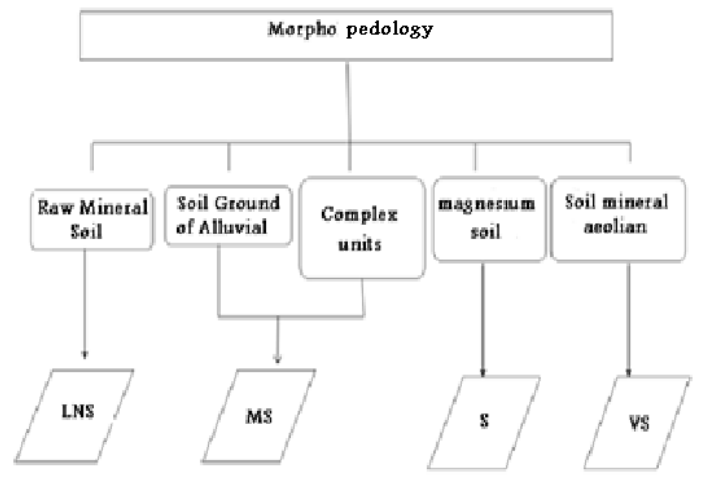

Fig.1.5: Degree of sensitivity of the Morpho pedology.

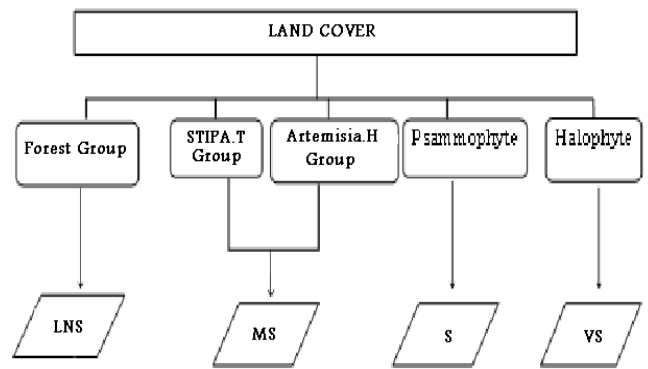

Fig.1.6: Degree of sensitivity of land Cover
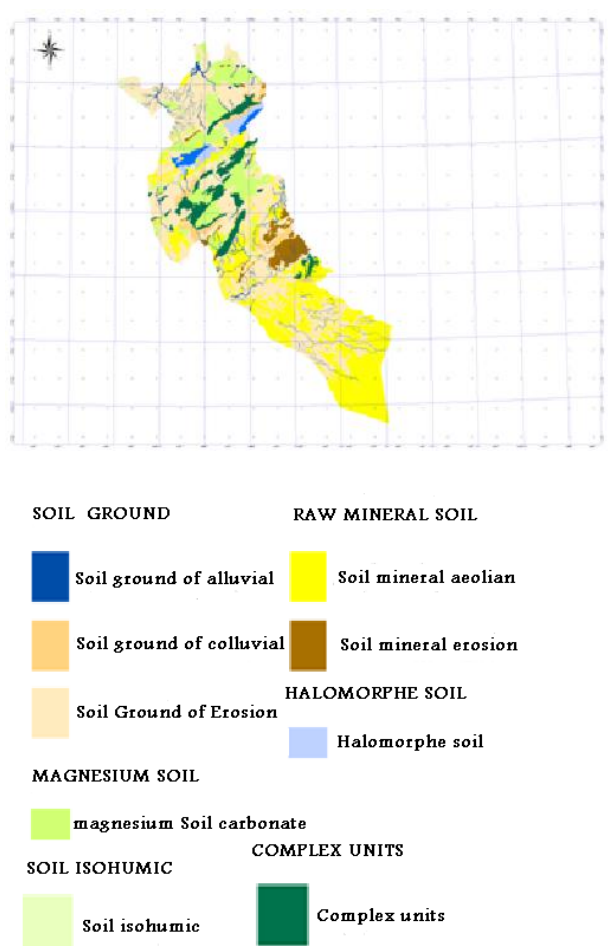

Fig. 1.8: Map of Morpho pedology of Djelfa region.

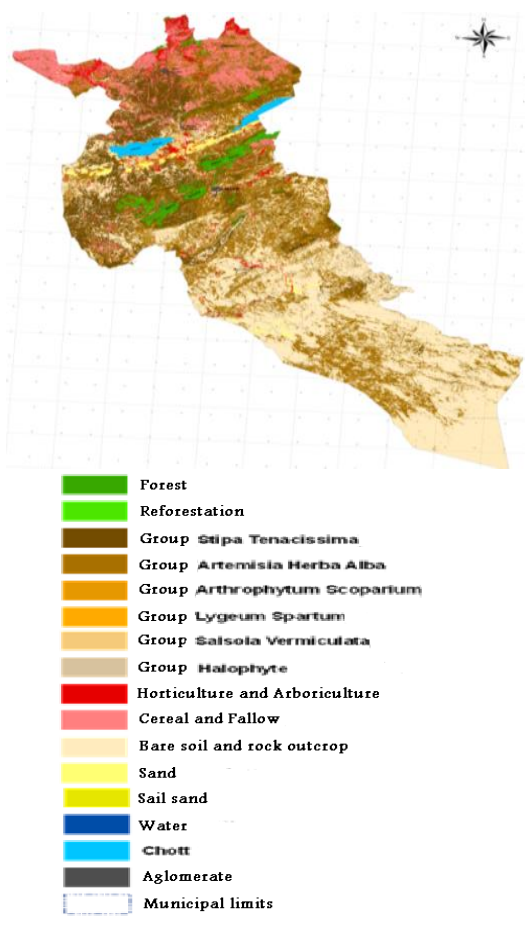

Fig. 1.7: Land Cover Map of Djelfa region

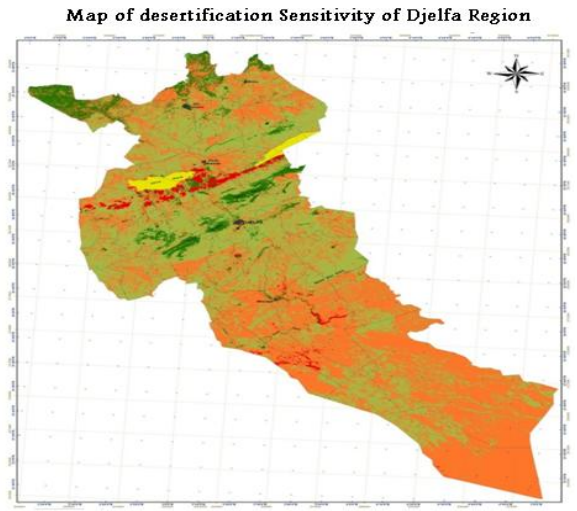

Little or No sensitive

Moderate Sensitive

Sensitive

Very Sensitive

Desertified

Fig.1.9: Map of sensitivity to desertification of Djelfa region. 
The interpretation of the results identified five classes of sensitivity to desertification are:

- $\quad$ Areas little or less sensitive to desertification: These are forest areas and forest occupying the in djebels. The soils are of two types: raw mineral soils and soil erosion unsophisticated mountain (rendzinas) under forest and scrub.

- Areas moderately sensitive to desertification: The soils are calcareous-magnesium and soil erosion has advanced, through a canopy (group Alfa and Artemisia).

- Areas sensitive to desertification: These are areas characterized by a vegetation gradient in much degraded (some groups to Psamophytes and bare soil), which concurrent on soil type and advanced unsophisticated.

- The areas very sensitive to desertification: These are mainly areas of Sand dune vegetation and soils Psamophytes highly degraded steppe.

- The desertified areas: These are the salt-pans (salt lakes and salt pans).

\begin{tabular}{|l|l|}
\hline \multicolumn{1}{|c|}{ Classe } & $\mathbf{\%}$ \\
\hline Little or less sensitive & 6,37 \\
\hline Moderate sensitive & 42,49 \\
\hline Sensitive & 48,43 \\
\hline Very Sensitive & 1,49 \\
\hline Desertified & 1,21 \\
\hline Total & $\mathbf{1 0 0}$ \\
\hline
\end{tabular}

\section{CONCLUSION}

The objective of this study was to apply a methodology combining multiple data sources to understand the phenomenon of desertification. The treatments performed on the data, have yielded the different thematic maps (land use, soil morphological). The integration of map data in a Geographic Information System and their intersection by a decision matrix, allowed us to produce results showing the area's most exposed to the problem of desertification. The final synthesis map that represents the sensitivity to desertification at Scale 1/200.000ème to serve as a tool for decision support for potential development projects in the steppe. It will also enable the monitoring and supervision of the steppe ecosystem. The multi-temporal analysis allows the identification of ecological change in relation to changes in land use in these sensitive areas.

\section{REFERENCES}

[1] Grainger, A., 1990, the threatening desert: controlling desertification, Earthscan, London;

[2] Olsson, G. W., 1981, Soils and the environment: A guide to soil surveys and their applications, Chapman and Hall, New York, N.Y., 200 p.

[3] INESG, 1988, Rapport de commission sur la désertification, Alger 1988.
[4] Rapport première phase désertification CNTS 1989 : mise au point méthodologique de cartographie de sensibilité à la désertification à un instant $\mathrm{t}$.

[5] Le Houerou, H.N ; 1962, Les pâturages de la Tunisie aride et désertique. ISEA - AN, TUNIS, 83 p.

[6] Mainguet, M ; 1990, La désertification : Une crise autant socio - économique que climatique. Sécheresse 1990, vol. 3, pp 197-195.

[7] Mainguet M ; (1994)- «Désertification : Quels sont les vrais problèmes ? »; L'information géographique $\mathrm{N}^{\circ} 2$ - Armande Colin, paris

[8] Pouget Marcel (1980)- «Les relations sol-végétation dans les steppes sud-algéroises ». O.R.S.T.O.M. paris.

Al: Guecemi Amine ; Yousfi Djaafar 